\title{
Resíduo de acerola em dietas para codornas
}

\author{
[Acerola residue in feed for quails] \\ T.S. Ferreira ${ }^{1}$, S.R.V. Lana ${ }^{2 *}$, G.R.Q. Lana ${ }^{2}$, J.A. Madalena ${ }^{3}$, L.C.L. Silva ${ }^{2}$, E.C. Torres ${ }^{2}$ \\ ${ }^{1}$ Universidade Federal da Paraíba - UFPB - Areia, PB \\ ${ }^{2}$ Universidade Federal de Alagoas - UFAL - Maceió, AL \\ ${ }^{3}$ Instituto Federal de Alagoas - IFAL - Satuba, AL
}

\begin{abstract}
RESUMO
Objetivou-se avaliar a inclusão do resíduo da acerola em dietas de codornas de corte sobre o desempenho produtivo, rendimento de carcaça, biometria intestinal e viabilidade econômica das aves, aos 42 dias de idade. Foram utilizadas 400 codornas europeias, não sexadas, de um dia de idade, distribuídas em delineamento experimental inteiramente ao acaso, com cinco níveis de inclusão $(0,0 ; 3,0 ; 6,0 ; 9,0$ e $12,0 \%)$ de resíduo da acerola, com oito repetições e 10 aves por unidade experimental. Não foram observadas diferenças significativas $(\mathrm{P}>0,05)$ para o ganho de peso, o consumo de ração, a conversão alimentar, os pesos absolutos e os rendimentos de carcaça e os cortes nobres (peito, coxa e sobrecoxa). Houve efeito $(\mathrm{P}<0,05)$ linear para os pesos absolutos e relativos de fígado e moela. A biometria intestinal das aves não foi $(\mathrm{P}>0,05)$ influenciada pelos níveis de inclusão do resíduo de acerola. O resíduo de acerola pode ser utilizado como ingrediente alternativo nas dietas de codornas europeias, até o nível de $12 \%$ de inclusão, sem comprometer o desempenho produtivo, o rendimento de carcaça das aves e a viabilidade econômica.
\end{abstract}

Palavras-chave: coturnicultura, Malpighiagalbra, subproduto da agroindústria

\begin{abstract}
The objective of this study was to evaluate the inclusion of the acerola residue in broiler quail diets on productive performance, carcass yield, intestinal biometry, and poultry economic viability at 42 days of age. Four hundred one-day unsexed European quail were distributed in a completely randomized experimental design with five inclusion levels (0.0, 3.0, 6.0, 9.0 and 12.0\%) of residue of acerola, with eight replicates and 10 birds per experimental unit.No significant differences $(P>0.05)$ were observed for weight gain, feed intake, feed conversion, absolute weights and carcass yields, and noble cuts (chest, thigh and sobrecoxa). There was a linear effect $(P<0.05)$ for absolute and relative weights of liver and gizzard. The intestinal biometry of the birds were not $(P>0.05)$ influenced by the inclusion levels of the acerola residue. The acerola residue can be used as an alternative ingredient in European quails diets up to a $12 \%$ inclusion level, without compromising productive performance, poultry carcass yield and economic viability.
\end{abstract}

Keywords: byproduction of agroindustry, Malpighia glabra, quail production

\section{INTRODUÇÃO}

No mercado consumidor, há crescente demanda por produtos alimentares provenientes de sistemas de produção que causam menos poluição ambiental (Santos et al., 2014). A investigação de novas tecnologias tem

Recebido em 15 de abril de 2017

Aceito em 22 de junho de 2017

*Autor para correspondência (corresponding author)

E-mail: sandraroselilana@gmail.com promovido, de forma significativa, o desenvolvimento da produtividade da indústria avícola. Em particular, estudos sobre alimentos alternativos permitiram a redução considerável nos custos de produção e, assim, têm contribuído para a redução da poluição ambiental (Albuquerque et al., 2014). 
No sistema de produção de aves, o gasto com a alimentação corresponde a aproximadamente $80 \%$ dos custos de produção. Logo, na formulação de rações balanceadas, devem-se buscar novos alimentos em substituição àqueles tradicionais, priorizando a redução de despesas, a qualidade e a disponibilidade regional do produto. Dentre os alimentos alternativos, têm-se os oriundos do beneficiamento das indústrias alimentícias, os quais geram subprodutos que podem ser utilizados na alimentação animal. Entre os subprodutos mais utilizados, estão os oriundos das indústrias de fruticulturas, como caju, abacaxi, maracujá, goiaba e acerola.

O resíduo da acerola, constituído por semente, casca e polpa, representa $40 \%$ do volume total da produção, sendo,portanto, produzidos mais de 3,5 milhões de toneladas de coprodutos anualmente (Pereira et al., 2009). O Brasil ocupa o primeiro lugar na produção e exportação da acerola (Malpghia glabra), em razão da existência de condições bastante favoráveis de clima e solo, além da importância nutricional dos frutos, que fez da acerola uma fruta altamente requisitada no mercado mundial para o preparo de sucos e consumo in natura, em virtude do seu alto teor de vitamina C (Souza et al., 2014; Furlaneto e Nasser, 2015).

Estudos realizados por Zanetti et al. (2014) demonstraram que o desempenho de frangos de cortes alimentados com dietas contendo até $10,25 \%$ de inclusão do resíduo da acerola melhorou a conversão alimentar e o ganho de peso das aves. Pinto et al. (2014) avaliaram a inclusão de resíduo de acerola nas dietas de frangos tipo colonial e constataram que a inclusão de até $10 \%$ do resíduo de acerola não comprometeu o desempenho produtivo das aves. Nesse contexto, objetivou-se avaliar a inclusão do resíduo de acerola na alimentação de codornas europeias sobre o desempenho produtivo, as características de carcaça, a biometria intestinal e a viabilidade econômica durante o período de um a 42 dias de idade.

\section{MATERIAL E MÉTODOS}

Todos os procedimentos deste estudo foram aprovados pelo Comitê de Ética no Uso de Animais da UFAL, sob número de protocolo
48/2015.O experimento foi realizado no setor de Coturnicultura do Centro de Ciências Agrárias da Universidade Federal de Alagoas - UFAL, localizado no município de Rio Largo - AL.

Utilizaram-se 400 codornas europeias, não sexadas, com um dia de idade, com peso médio inicial $8,55 \pm 0,93 \mathrm{~g}$, alojadas em gaiolas do tipo bateria,com $50 \mathrm{~cm}$ de comprimento, $60 \mathrm{~cm}$ de largura e $30 \mathrm{~cm}$ de altura,em galpão com piso de concreto durante o período de um a 42 dias de idade. A alimentação foi fornecida em comedouros e bebedouros próprios para a fase de criação; a ração e a água foram fornecidasad libitum durantetodo o período experimental. O delineamento adotado foi inteiramente ao acaso, com cinco tratamentos $(0,00 ; 3,0 ; 6,0 ; 9,0$ e $12,0 \%$ de inclusão do resíduo de acerola), oito repetições e 10 aves por unidade experimental.

As rações experimentais foram formuladas à base de milho e farelo de soja, visando atender às exigências nutricionais das aves, segundo recomendações preconizadas por Rostagnoet al. (2011), sendo isocalóricas e isonutritivas(Tab. 1). Para a inclusão do resíduo da acerola nas rações formuladas, foram considerados os valores de composição bromatológica determinados por Pereira et al. (2009). O valor de energia metabolizável utilizado foi $754 \mathrm{kcal} / \mathrm{kg}$, preconizado por Zanetti et al. (2011). O resíduo da acerola, composto por sementes, cascas e polpa, foi oriundo do processamento agroindustrial da acerola, fornecido por uma indústria de sucos local. $\mathrm{O}$ processamento foi feito por meio de secagem ao sol por oito horas, durante cinco dias, e o resíduo foi moído em forma de farelo para a inclusão na ração das aves.

O monitoramento da temperatura e da umidade relativa do ar foi realizado por termo-higrômetro digital, situado na altura das gaiolas, realizandose as leituras diariamente nos horários de oito e 16 horas. O programa de luz adotado foi o contínuo, 24 horas de luz, utilizando lâmpadas incandescentes de $40 \mathrm{~W}$. As médias das variáveis foram: temperatura máxima $27,61^{\circ} \mathrm{C}$, temperatura mínima $26,01^{\circ} \mathrm{C}$, umidade relativa $77 \%$ e o índice de temperatura de globo negro e umidade 76,84, calculado de acordo com a fórmula proposta por Buffingtonet al. (1981). 
Tabela 1.Composição percentual, energética e químicadas rações experimentais para codornas

\begin{tabular}{|c|c|c|c|c|c|}
\hline \multirow{2}{*}{ Ingredientes $(\%)$} & \multicolumn{5}{|c|}{ Níveis de inclusão do resíduo da acerola (\%) } \\
\hline & 0,0 & 3,0 & 6,0 & 9,0 & 12,0 \\
\hline Milho & 57,118 & 53,355 & 49,593 & 45,830 & 42,067 \\
\hline Farelo de soja ( $45 \%)$ & 37,604 & 37,025 & 36,447 & 35,868 & 35,290 \\
\hline Resíduo da acerola & 0,000 & 3,000 & 6,000 & 9,000 & 12,00 \\
\hline Fosfato bicálcico & 1,394 & 1,413 & 1,432 & 1,451 & 1,470 \\
\hline Calcáriocalcítico & 1,163 & 1,118 & 1,073 & 1,028 & 0,984 \\
\hline Sal comum & 0,390 & 0,395 & 0,400 & 0,402 & 0,404 \\
\hline Óleo de soja & 1,090 & 2,389 & 3,688 & 4,988 & 6,000 \\
\hline DL-metionina & 0,172 & 0,190 & 0,208 & 0,226 & 0,244 \\
\hline L-lisina $\mathrm{HCl}$ & 0,414 & 0,442 & 0,470 & 0,498 & 0,526 \\
\hline L-treonina & 0,461 & 0,065 & 0,085 & 0,104 & 0,124 \\
\hline Suplemento vitamínico ${ }^{1}$ & 0,050 & 0,050 & 0,050 & 0,050 & 0,050 \\
\hline Suplemento mineral ${ }^{2}$ & 0,100 & 0,100 & 0,100 & 0,100 & 0,100 \\
\hline Material inerte & 0,044 & 0,458 & 0,454 & 0,455 & 0,741 \\
\hline TOTAL & 100,00 & 100,00 & 100,00 & 100,00 & 100,00 \\
\hline Custo/kg ração & 1,68 & 1,64 & 1,65 & 1,38 & 1,38 \\
\hline \multicolumn{6}{|c|}{ Composição calculada } \\
\hline Energia met. aves (kcal/kg) & 2.900 & 2.900 & 2.900 & 2.900 & 2.900 \\
\hline Proteína bruta $(\%)$ & 22,00 & 22,00 & 22,00 & 22,00 & 22,00 \\
\hline Cálcio total $(\%)$ & 0,900 & 0,900 & 0,900 & 0,900 & 0,900 \\
\hline Fósforo disponível (\%) & 0,375 & 0,375 & 0,375 & 0,375 & 0,375 \\
\hline Fibra bruta & 2,98 & 3,68 & 4,39 & 5,09 & 5,79 \\
\hline Sódio $(\%)$ & 0,176 & 0,176 & 0,176 & 0,176 & 0,176 \\
\hline Metionina total $(\%)$ & 0,460 & 0,460 & 0,460 & 0,460 & 0,460 \\
\hline Metionina digestível (\%) & 0,420 & 0,420 & 0,420 & 0,420 & 0,420 \\
\hline Met.+cistina total (\%) & 0,844 & 0,844 & 0,844 & 0,844 & 0,844 \\
\hline Lisina total $(\%)$ & 1,244 & 1,244 & 1,244 & 1,244 & 1,244 \\
\hline Lisina digestível (\%) & 1,120 & 1,120 & 1,120 & 1,120 & 1,120 \\
\hline Treonina total $(\%)$ & 0,915 & 0,915 & 0,915 & 0,915 & 0,915 \\
\hline Treonina digestível (\%) & 0,790 & 0,790 & 0,790 & 0,790 & 0,790 \\
\hline
\end{tabular}

${ }^{1}$ Suplemento vitamínico/kg: vit.A 13.440,000UI; vit. D 3.200,000UI;vit.E 28.000mg/kg; vit.K 2.880mg/kg; tiamina $3.500 \mathrm{mg} / \mathrm{kg}$; riboflavina $9.600 \mathrm{mg} / \mathrm{kg}$; piridoxina $5.000 \mathrm{mg} / \mathrm{kg}$; cianocobalamina $19.200 \mathrm{mcg} / \mathrm{kg}$; ácido fólico $1.600 \mathrm{mg} / \mathrm{kg}$; ácido pantotênico $25,000 \mathrm{mg} / \mathrm{kg}$; niacina $67.200 \mathrm{mg} / \mathrm{kg}$; biotina $80.000 \mathrm{mcg} / \mathrm{kg}$; selênio $600 \mathrm{ppm}$; antioxidante 0,40g/kg. ${ }^{2}$ Suplemento mineral $/ \mathrm{kg}$ : Mg 150.000ppm; Zn 140.000ppm; Fe 100.000ppm; Cu 16.000ppm; I $1.500 \mathrm{ppm}$.

As variáveis avaliadas durante o período experimental foram: ganho de peso, consumo de raçãoe conversão alimentar, rendimento de carcaça, de cortes e visceras, e a biometria intestinal. As aves, a ração fornecida e as sobras de ração foram pesadas semanalmente para o cálculo dos índices de desempenho.

Aos 42 dias de idade, as aves foram pesadas após jejum alimentar de seis horas, sendo selecionadas duas aves por unidade experimental, com peso vivo próximo da média de peso observado para a referida gaiola, para posterior realização dos procedimentos normais de abate (atordoamento, sangria e depenagem), conforme preconizados pelo Regulamento de Inspeção Industrial e
Sanitária dos Produtos de Origem Animal (Brasil, 1997). As aves foram evisceradas, as carcaças e as vísceras foram pesadas, paraposteriormente proceder-se àavaliaçãodo rendimento de carcaça. Os parâmetros avaliados foram: pesos absolutos (g) e relativos (\%) da carcaça, de cortes nobres (peito e pernas) e das vísceras comestíveis (coração, fígado e moela).

Para avaliação da biometria intestinal, cinco aves de peso médio foram selecionadas de cada tratamento e abatidas após jejum de duas horas para realização dos procedimentos de pesagem, mensuração do comprimento intestinal. Os intestinos das aves foram pesados em balança de precisão e medidos com auxílio de fita métrica. 
As variáveis estudadas foram avaliadas utilizando-se o software $\mathrm{R}$ Core Team ( $\mathrm{R}$ Development..., 2016), por meio de análise de variância e, em caso de significância $(\mathrm{P}<0,05)$, modelos de regressão foram utilizados para avaliar o melhor nível de inclusão do resíduo de acerola.

A análise econômica foi realizada de acordo com a metodologia descrita por Lana, (2000). A avaliação econômica das rações experimentais foi baseada nos dados de desempenho das aves. O preço codorna viva/kg $(\mathrm{R} \$ 11,50)$ e os valores das matérias-primas utilizadas para o cálculo dos custos das rações, referem-se aos valores vigentes no comércio local (março de 2016). Os preços dos ingredientes $(\mathrm{kg})$ utilizados na elaboração dos custos das rações foram: milho
$\mathrm{R} \$$ 0,90; farelo de soja $\mathrm{R} \$ 1,28$; resíduo da acerola $\mathrm{R} \$ 0,25$; fosfato bicálcico $\mathrm{R} \$ 2,30$; calcário $\mathrm{R} \$ 2,30$; sal $\mathrm{R} \$ 0,75$; óleo de soja $\mathrm{R} \$$ 2,90; DL-metionina $\mathrm{R} \$ 50,00$; L-lisina $\mathrm{HCl} \mathrm{R} \$$ 35,00; L-treonina $\mathrm{R} \$ 15,00$; premix vitamínico $\mathrm{R} \$ 15,00$; premix mineral $\mathrm{R} \$ 10,00$; inerte $\mathrm{R} \$$ 0,14 .

\section{RESULTADOS E DISCUSSÃO}

Não houve influência $(\mathrm{P}>0,05)$ dos níveis de inclusão do resíduo de acerola sobre o consumo de ração, o ganho de peso e a conversão alimentar das aves nos períodos de um a 21; 22 a 42 e um a 42 dias de idade (Tab.2).Esse resultado sugere que a utilização de resíduo de acerola não comprometeu o desempenho produtivo das codornas.

Tabela 2.Desempenho de codornas de corte alimentadas com diferentes níveis de inclusão do resíduo da acerola na dieta

\begin{tabular}{|c|c|c|c|c|c|c|c|}
\hline \multirow{3}{*}{ Parâmetros } & \multicolumn{7}{|c|}{ Níveis de inclusão do resíduo da acerola $(\%)^{\text {ns }}$} \\
\hline & 0,0 & 3,0 & 6,0 & 9,0 & 12,0 & P-valor & $\mathrm{CV}(\%)$ \\
\hline & \multicolumn{7}{|c|}{01 a 21 dias de idade } \\
\hline Consumo de ração (g/ave) & 266,50 & 268,50 & 274,93 & 276,31 & 276,68 & 0,13 & 3,55 \\
\hline Ganho de peso (g/ave) & 132,58 & 131,51 & 134,07 & 134,97 & 135,45 & 0,23 & 2,86 \\
\hline Conversão alimentar & 2,01 & 2,04 & 2,05 & 2,05 & 2,04 & 0,78 & 3,64 \\
\hline \multicolumn{8}{|c|}{22 a 42 dias de idade } \\
\hline Consumo de ração (g/ave) & 546,20 & 547,06 & 560,94 & 599,61 & 562,89 & 0,81 & 6,58 \\
\hline Ganho de peso (g/ave) & 108,18 & 106,28 & 111,71 & 106,79 & 111,82 & 0,63 & 8,64 \\
\hline Conversão alimentar & 5,06 & 5,16 & 5,02 & 5,23 & 5,06 & 0,62 & 5,92 \\
\hline \multicolumn{8}{|c|}{01 a 42 dias de idade } \\
\hline Consumo de ração (g/ave) & 812,70 & 815,56 & 835,88 & 835,92 & 839,58 & 0,52 & 4,80 \\
\hline Ganho de peso (g/ave) & 240,76 & 237,80 & 245,79 & 241,77 & 247,28 & 0,43 & 4,45 \\
\hline Conversão alimentar & 3,37 & 3,43 & 3,40 & 3,45 & 3,39 & 0,60 & 3,09 \\
\hline
\end{tabular}

${ }^{\mathrm{ns}}$ não significativo( $\left.\mathrm{P}>0,05\right)$.

Embora não tenha ocorrido efeito $(\mathrm{P}>0,05)$ dos níveis de inclusão de resíduo de acerola, pode-se observar, em valores absolutos, aumento de $3,20 \%$ no consumo de ração e de $2,64 \%$ no ganho de peso das aves aos 42 dias de idade. Por outro lado, verificou-se piora de $0,59 \%$ na conversão alimentar à medida que se elevou o nível do resíduo de acerola nas dietas. $\mathrm{O}$ fato de o resíduo de acerola possuir alto teor de fibras contribuiu para essa resposta, visto que a elevada quantidade de fibras é um fator diluidor de outros nutrientes, atua como barreira física, impedindo que as enzimas endógenas tenham acesso ao conteúdo interno das células vegetais, causando a redução do processo digestivo e, consequentemente, a absorção dos nutrientes
(Jansen e Carré, 1989), acarretando em aumento no consumo de ração das aves, a fim de compensar o aporte energético.

Murakami et al.(1993) justificou esse fato quando afirmou que, para codornas, é possível aplicar a teoria quimiostática, ou seja, a de que os animais regulam seu consumo de acordo com a necessidade de energia, no entanto outros fatores também podem influenciar o consumo, como a necessidade da ave, o peso corporal, a fase produtiva, o crescimento, a mantença e o ambiente de criação.

Os resultados obtidos no presente estudo corroboraram os encontrados por Zanetti et al. 
(2014) ao avaliarem a inclusão do resíduo da acerola em dietas para frangos de corte. Resultados semelhantes foram obtidos por Ramos et al. (2006), que recomendaram a inclusão de até $15 \%$ de polpa de caju desidratada para frangos de corte. Da mesma forma, Lira et al. (2010) e Camelo et al. (2015) não encontraram efeitos significativos sobre o desempenho produtivo ao avaliarem os níveis de inclusão do resíduo de goiaba na alimentação de frangos de corte e de codornas, respectivamente. Por outro lado, Pinto et al. (2014) e Zanetti et al. (2014) encontraram diferenças significativas no ganho de peso, na conversão alimentar e na viabilidade de frangos de corte aos 42 dias de idade,com a inclusão do coproduto da acerola às rações.

Torna-se relevante considerar que, em razão de o resíduo de acerola ser um ingrediente com baixo conteúdo energético $(754 \mathrm{kcal}$ de $\mathrm{EM} / \mathrm{kg})$, fez-se necessária a adição de óleo vegetal para suprir as exigências energéticas das codornas, uma vez que, com a elevação de níveis de inclusão do coproduto, ocorre a redução da fonte energética (milho)das dietas experimentais.Com o intuito de manter o balanço energético, Ramos et al. (2006) e Zanetti et al. (2014) recomendaram a adição de óleo vegetal às dietas contendo polpa de caju desidratada e resíduo de acerola, respectivamente, para frangos de corte.

O peso absoluto ao abate, os pesos absolutos e relativos de carcaça e os cortes nobres das codornas aos 42 dias de idade não foram ( $\mathrm{P}>0,05)$ influenciados pelos diferentes níveis de inclusão do resíduo da acerola (Tab. 3), evidenciando que a inclusão do resíduo de acerola não interferiu negativamente sobre $o$ rendimento de carcaça. Embora não tenha ocorrido efeito dos níveis de inclusão do resíduo de acerola, pode-se observar, em valores absolutos, que as aves alimentadas com $12 \%$ apresentaram os maiores pesos quando estes foram comparados aos pesos daquelas que receberam rações contendo os demais níveis. Resultados semelhantes foram obtidos por Cameloet al. (2015), que recomendaram a inclusão de até $10 \%$ de resíduo de goiaba em dietas para codornas sem comprometer o desempenho produtivo e o rendimento de carcaça.

Tabela 3.Valores de pesos absolutos e relativos de carcaça, cortes e vísceras comestíveis de codornas europeias aos 42 dias de idade

\begin{tabular}{|c|c|c|c|c|c|c|c|}
\hline \multirow{3}{*}{ Variáveis } & \multicolumn{7}{|c|}{ Níveis de inclusão do resíduo de acerola (\%) } \\
\hline & 0,0 & 3,0 & 6,0 & 9,0 & 12,0 & P-valor & $\mathrm{CV}(\%)$ \\
\hline & \multicolumn{7}{|c|}{ Peso absoluto $(\mathrm{g})$} \\
\hline Peso ao abate & 236,25 & 227,81 & 231,25 & 237,18 & 246,56 & 0,53 & 7,92 \\
\hline Carcaça & 171,67 & 166,64 & 169,85 & 175,74 & 174,80 & 0,29 & 7,69 \\
\hline Peito & 67,36 & 64,79 & 66,37 & 68,24 & 68,48 & 0,57 & 10,52 \\
\hline Dorso & 50,27 & 47,08 & 50,41 & 49,99 & 50,22 & 0,52 & 12,68 \\
\hline Pernas & 36,52 & 35,49 & 35,24 & 36,51 & 37,07 & 0,49 & 9,24 \\
\hline Asas & 13,92 & 13,97 & 13,78 & 14,44 & 13,72 & 0,74 & 11,51 \\
\hline Coração & 1,87 & 1,78 & 1,93 & 1,84 & 1,80 & 0,45 & 13,41 \\
\hline Fígado & 4,48 & 4,30 & 4,24 & 4,05 & 3,75 & $0,04 *$ & 17,18 \\
\hline Moela & 2,29 & 2,48 & 2,48 & 2,51 & 2,55 & 0,07 & 10,75 \\
\hline \multicolumn{8}{|c|}{ Peso relativo $(\%)$} \\
\hline Carcaça & 73,22 & 73,43 & 74,19 & 74,62 & 74,07 & 0,93 & 6,99 \\
\hline Peito & 39,19 & 39,02 & 39,11 & 38,84 & 39,18 & 0,99 & 8,92 \\
\hline Dorso & 29,30 & 28,19 & 29,65 & 28,44 & 28,67 & 0,44 & 8,65 \\
\hline Pernas & 21,29 & 21,35 & 20,74 & 20,76 & 21,25 & 0,58 & 6,75 \\
\hline Asas & 8,13 & 8,41 & 8,12 & 8,23 & 7,88 & 0,65 & 11,99 \\
\hline Coração & 1,09 & 1,06 & 1,14 & 1,05 & 1,03 & 0,16 & 11,49 \\
\hline Fígado & 2,60 & 2,60 & 2,51 & 2,19 & 2,14 & $0,01 *$ & 18,14 \\
\hline Moela & 3,93 & 4,12 & 4,19 & 4,41 & 4,44 & $0,002 *$ & 9,13 \\
\hline
\end{tabular}

*Efeito Linear $(\mathrm{P}<0,05)$. 
Lira et al. (2010)), ao estudarem a inclusão do resíduo de goiaba para frangos de corte, também não constataram efeito significativo sobre o rendimento de carcaça. Do mesmo modo, Freitas et al. (2011), quando estudaram a substituição do farelo de soja pelo farelo de coco em rações contendo farelo de castanha do caju para frangos de corte, não observaram efeito significativo para o rendimento de carcaça dessas aves.

Houve efeito $(\mathrm{P}<0,05)$ dos níveis de inclusão do resíduo de acerola sobre os pesos absolutos e relativos do fígado e da moela (Tab.3). Os níveis de inclusão do resíduo de acerola não influenciaram $(\mathrm{P}>0,05)$ os pesos absolutos $\mathrm{e}$ relativos do coração das aves. Foi observado efeito linear $(\mathrm{P}<0,05)$ nos pesos absoluto e relativo do fígado, em que cada $1 \%$ de inclusão do subproduto da acerola conferiu uma redução de $0,06 \mathrm{~g} /$ ave no peso absoluto e de $0,04 \mathrm{~g}$ /ave no peso relativo do fígado, segundo as respectivas equações: $\hat{\mathrm{Y}}=4,5158-0,0558 \mathrm{X}\left(\mathrm{R}^{2}=0,94\right)$; $\hat{\mathrm{Y}}=2,6825-0,0415 \mathrm{X}\left(\mathrm{R}^{2}=0,90\right)$.

A redução do tamanho do fígado foi ocasionada, provavelmente, pelo aumento do teor de gordura nas dietas contendo maior nível do resíduo da acerola, resultando em redução da lipogênese e, consequentemente, menor desenvolvimento do órgão. Resultados semelhantes foram obtidos por Pinto et al. (2014), que observaram redução no peso do fígado e aumento no peso da moela de frangos de corte alimentados com resíduo da acerola. Contrariamente, Lira et al. (2010)) e Camelo et al. (2015) não constataram efeito da inclusão de resíduo de goiaba sobre o rendimento de fígado das aves.
Constatou-se efeito linear dos níveis do resíduo da acerola sobre o peso relativo da moela, em que severificou um aumento de $0,04 \mathrm{~g} /$ ave a cada $1 \%$ de inclusão do resíduo da acerola, conforme a equação: $\hat{Y}=3,9628+0,0360 X \quad\left(R^{2}=0,95\right) . O$ aumento do tamanho da moela ocorreu pelo aumento do teor de fibras nas dietas de maior nível do resíduo da acerola, que pode ser justificado, possivelmente, pela maior granulometria e quantidade de fibra das rações, pois o resíduo de acerola é constituído por casca, polpa, e sementes, o que pode ter provocado maiores contrações dos músculos da moela, promovendo, assim, maior massa muscular (González et al., 2007). Resultados semelhantes foram obtidos por Pinto et al. (2014), que observaram aumento da moela entre os níveis testados com resíduo de acerola para frangos de corte. Lira et al. (2010) constataram aumento no peso relativo da moela de frangos de corte à medida que se elevou o nível de subproduto da goiaba para $10 \%$ de inclusão.

Dentro do contexto, pode-se inferir que a composição química do resíduo de acerola não influenciou de forma negativa a digestibilidade dos nutrientes e consequentemente o desempenho e o rendimento de carcaça das aves até o nível de $12 \%$ de inclusão.

Os resultados para peso $(\mathrm{g})$ e comprimento $(\mathrm{cm})$ intestinal das codornas de corte abatidas aos 42 dias de idade não apresentaram diferenças significativas $(\mathrm{P}>0,05)$ entre os níveis de inclusão do resíduo da acerola (Tab.4). Resultados semelhantes foram encontrados por Saaret al. (2015), que não encontraram efeitos sobre o peso e o tamanho dos intestinos grosso e delgado de codornas alimentadas com dietas à base de sorgo.

Tabela 4. Biometria intestinal de codornas de corte aos 42 dias de idade, alimentadas com resíduo de acerola

\begin{tabular}{llllllll}
\hline \multicolumn{1}{c}{ Variáveis } & \multicolumn{5}{c}{ Níveis de inclusão do resíduo (\%) $^{\mathrm{ns}}$} \\
\cline { 2 - 8 } & 0,0 & 3,0 & 6,0 & 9,0 & 12,0 & P-valor & CV $(\%)$ \\
\hline Intestino delgado $(\mathrm{cm})$ & 46,4 & 47,4 & 48,8 & 49,1 & 49,6 & 0,80 & 10,21 \\
Intestino delgado $(\mathrm{g})$ & 2,777 & 2,860 & 2,871 & 2,974 & 3,263 & 0,22 & 11,58 \\
Intestino grosso $(\mathrm{cm})$ & 10,0 & 9,8 & 11,5 & 11,0 & 11,2 & 0,23 & 12,69 \\
Intestino grosso $(\mathrm{g})$ & 1,067 & 1,096 & 1,296 & 1,450 & 1,440 & 0,19 & 24,48 \\
Comprimento total $(\mathrm{cm})$ & 56,5 & 56,8 & 60,3 & 60,2 & 60,8 & 0,53 & 8,87 \\
Peso total $(\mathrm{g})$ & 3,845 & 3,922 & 4,168 & 4,424 & 4,703 & 0,07 & 11,59 \\
\hline
\end{tabular}

${ }^{\text {ns }}$ ão significativo $(\mathrm{P}>0,05)$. 
O maior peso do intestino das aves que receberam as dietas contendo maior nível de fibras insolúveis pode ser associado aos efeitos negativos da maior quantidade de fibra sobre a digestão e a absorção de nutrientes. Esses efeitos induzem maior atividade desse órgão na tentativa de melhorar a digestão e a absorção com dietas de alta viscosidade, acarretando maior desenvolvimento dos órgãos. De acordo com Gomes et al. (2007), uma forma de o metabolismo animal responder a uma melhor absorção de nutrientes do alimento ingerido seria um maior desenvolvimento do intestino delgado, ou seja, quanto maior o seu comprimento, mais extenso é a área de exposição dos nutrientes às células absortivas, resultando em melhor utilização dos nutrientes para formação de músculos. Furlan et al. (2001) afirmaram que a melhor utilização dos alimentos está diretamente relacionada com a estrutura do sistema digestório, em especial do intestino delgado. Diante disso, os nutrientes, bem como o programa nutricional, podem gerar mudanças no perfil de crescimento desse trato digestório.

O nível de $12,0 \%$ de inclusão do resíduo da acerola apresentou superioridade para a renda média bruta ( $\mathrm{R} \$ 2,84)$, que representa $\mathrm{o}$ montante recebido por codorna alimentada, em relação à comercialização das aves alimentadas com os demais níveis (Tab. 5).

Tabela 5.Análise econômica dos níveis de inclusão do resíduo da acerola em relação ao peso vivo das aves aos 42 dias de idade

\begin{tabular}{ccccccc}
\hline \multicolumn{7}{c}{ Variáveis econômicas } \\
\hline Níveis (\%) & RBM & MBM & MBR & RM & IRR & IBEP \\
\hline 0,0 & 2,77 & 1,40 & 100,00 & 101,90 & 100,00 & 0,1161 \\
3,0 & 2,73 & 1,39 & 99,44 & 103,25 & 101,33 & 0,1155 \\
6,0 & 2,83 & 1,44 & 103,32 & 104,42 & 102,48 & 0,1200 \\
9,0 & 2,78 & 1,39 & 99,78 & 100,61 & 98,74 & 0,1157 \\
12,0 & 2,84 & 1,45 & 104,13 & 104,80 & 102,85 & 0,1210 \\
\hline
\end{tabular}

${ }^{1}$ Níveis de inclusão do resíduo da acerola;RBM = renda bruta média (R\$/ave); $\mathrm{MBM}=$ margem bruta média $(\mathrm{R} \$ /$ ave $) ; \mathrm{MBR}=$ margem bruta relativa $(\%) ; \mathrm{RM}=$ rentabilidade média $(\%) ; \mathrm{IRR}=$ índice relativo de rentabilidade em relação ao tratamento $1(\%) ;$ IBEP = índice bioeconômico ponderado.

Houve superioridade dos níveis 12 e $6,0 \%$ de inclusão do resíduo da acerola para a margem bruta média e a margem bruta relativa, respectivamente. A rentabilidade média e o índice relativo de rentabilidade foram maiores para o nível de $12,0 \%$ do resíduo de acerola em relação aos demais níveis de inclusão avaliados.O uso do resíduo de acerola na alimentação de codornas pode ser vantajoso durante períodos de entressafra, quando os preços dos ingredientes tradicionais, como milho e farelo de soja, estão elevados. Dentro desse contexto, a utilização de ingredientes alternativos está diretamente ligada ao preço das matériasprimas, bem como o custo de uma possível suplementação necessária para manter níveis nutricionais adequados para o desempenho das codornas.

\section{CONCLUSÕES}

Recomenda-se a inclusão de até $12,0 \%$ do resíduo de acerola em rações de codornas de corte, sem comprometer o desempenho produtivo, durante o período de um a 42 dias de idade.

\section{REFERÊNCIAS}

ALBUQUERQUE, C.S.; RABELLO, C.B.V.; SANTOS, M.J.B. et al. Chemical composition and metabolizable energy values of corn germ meal obtained by wet milling for layers. Rev. Bras. Cienc. Avic., v.16, p.107-112, 2014.

BRASIL. Ministério da Agricultura, Pecuária e Abastecimento. Regulamento de Inspeção Industrial e Sanitária de Produtos de Origem Animal. Decreto $n^{\circ}$ 30.691, de 29 de março de 1952, e alterações. Diário Oficial da União. Brasília, 1997. Disponível em: <www.agricultura.gov.br>. Acessado em: 27 de dezembro de 2016.

BUFFINGTON, D.E.; COLLAZO-AROCHO, A.; CANTON, G.H. et al. Black globe-humidity index (BGHI) as comfort equation for dairy cows. Trans. Am. Soc. Agric. Biol. Eng., v.24, p.711-714, 1981.

CAMELO, L.C.; LANA, G.R.Q.; SANTOS, M.J.B. et al. Inclusion of guava wastes in the diet of European quails. Cienc. Anim. Bras., v.16, p.343-349, 2015. 
FREITAS, E.R.; LIMA, R.C.; SILVA, R.B. et al. Substituição do farelo de soja pelo farelo de coco em rações contendo farelo da castanha de caju para frangos de corte. Rev. Bras. Zootec., v.40, p.10061013,2011

FURLAN, R.L.; CARVALHO, N.C.; MALHEIROS, E.B.; MACARI, M. Efeito da restrição alimentar inicial e da temperatura ambiente sobre o desenvolvimento de vísceras e ganho compensatório em frangos de corte. Arq. Bras. Med. Vet. Zootec., v.53, p.1-9, 2001.

FURLANETO, F.P.B.; NASSER, M.D. Panorama da cultura da acerola no estado de São Paulo. Pesqui. Tecnol., v.12, 2015. Disponível em: <http://www.aptaregional.sp.gov.br>. Acessado em: 10 set. 2016

GOMES, J.D.F.; PUTRINO, S.M.; MARTELLI, M.R. et al. Morfologia de órgãos digestivos de suínos de linhagens modernas durante as fases de crescimento, terminação e pós-terminação. Acta Sci. Anim. Sci., v.29, p.261-266, 2007.

GONZÁLEZ-ALVARO, J.M.; JIMÉNEZ-MORENO, E.; LÁZARO, R.; MATEOS, G.G. Effect of type of cereal, heat processing of the cereal, and inclusion of fiber in the diet on performance and digestive traits of broilers. Poult. Sci., v.86, p.1705-1715, 2007.

JANSEN, W.M.M.A.; CARE, B. Influence of fiber on digestibility of poultry feedes. In: COLE, D.J.A; HARESIGN, W. Recent developments in poultry nutrition. London: Butterworths, 1989. p.78-93.

LANA, G.R.Q. Avicultura. Recife: UFRPE, 2000. 268 p.

LIRA, R.C.; RABELLO, C.B.V.; LUDKE, M.C.M.M et al. Productive performance of broiler chickens fed tomato waste. Rev. Bras. Zootec., v.39, p.1074-1081, 2010 .

MURAKAMI, A.E.; MORAES, V.M.B.; ARIKI, J. Níveis de proteína e energia em dietas de codornas japonesas (CoturnixCoturnixjaponica) em postura. Rev. Bras. Zootec., v.22, p.541-551, 1993.

PEREIRA, L.G.R.; AZEVEDO, J.A.G.; PINA, D.S. et al.Aproveitamento dos coprodutos da agroindústria processadora de suco e polpa de frutas na alimentação de ruminantes. Petrolina: Embrapa Semiárido, 2009. 30p. (Documento n.220). Disponível em: <http://www.cpatsa.embrapa.br:8080/publiceletronica/ downloads/SDC220.pdf>. Acessado em: 16 set. 2016.
PINTO, M.F.; MOREIRA, A.J.C.; BOSSOLANI, I.L.C.et al. Production of slow growing broiler chicken using by-product from fruit juice processing. Arch. Latinoam. Prod. Anim., v.22, p.32-35, 2014.

$\mathrm{R}$ DEVELOPMENT core team: a language and environment for statistical computing. Vienna: $\mathrm{R}$ Foundation for Statistical Computing, 2016.

RAMOS, L.S.N.; LOPES, J.B.; FIGUEIREDO, A.V. et al. Polpa de caju em rações para frangos de corte na fase final: desempenho e características de carcaça. Rev. Bras. Zootec., v.35, p.804-810, 2006.

ROSTAGNO, H.S.; ALBINO, L.F.T.; DONZELE, J.L. et al. Tabelas brasileiras para aves e suínos: composição de alimentos e exigências nutricionais. 3.ed. Viçosa, MG: UFV, 2011. 252p.

SAAR, A.G.L.; MORAES, C.A.; FERNANDES, E.A. et al. Morfometria do trato gastrintestinal de codornas de corte alimentadas com dieta a base de sorgo grão. Encicl. Biosfera, v.11, p.2288, 2015.

SANTOS, M.J.B.; PANDORFI, H.; RABELLO, C.B.V. et al.Performance of free-range chickens reared in production modules enriched with shade nets and perches. Rev. Bras. Cienc. Avic., v.16, p.19-28, 2014.

SOUZA, A.C.L.; AQUINO, N.S.M.; OLIVEIRA, T.K.L.; ALMEIDA, E.B.Elaboração de biscoitos da farinha de resíduos de acerola Malpghia glabra e estudo dos seus componentes físico-químicos. In:CONGRESSO BRASILEIRO DE PROCESSAMENTO DE FRUTAS E HORTLIÇAS, 3., 2014, Ilhéus. Anais... Ilhéus: Magistra, 2014. v.26. Disponível <https://www.ufrb.edu.br/magistra/2000atual/volume-26.../download>. Acessado em: 13 abr. 2016.

ZANETTI, L.H.; CRUZ, V.C.; POLYCARPO, G.V. et al. Nutritional value of acerola meal for broiler chickens. J. Anim. Sci., v.89, p.333, 2011.

ZANETTI, L.H.; POLYCARPO, G.V.; BRICHI, A.L.C. et al. Performance and economic analysis of broilers fed diets containing acerola meal in replacement of corn. Braz. J. Vet. Res. Anim. Sci., v.51, p.224-232, 2014. 